closed; and the space which these four blades occupy is considerably less than even the very smallest-sized Ferguson speculum, while at the same time it admits of the blades being expanded to an extent equal to the capacity of almost any vagina.

There are two other great advantages possessed by these instruments which I ought to mention. In the first place, they admit of a digital examination being made simultaneously with the specular. And, secondly, especially with the four-bladed instrument, a variety of operations, including those for vesico- and recto-vaginal fistula, can be performed without the help of an assistant in holding the speculum, with a far better view of the parts concerned, and therefore with more ease to the operator.

It might be urged as objections to these instrumentsfirst, that by the loss of so much reflecting surfaceinspection would be difficult for want of light; and, secondly, that between the blades the vaginal folds are liable to collapse, and so to obstruct the view. The first of these objections I have already anticipated. Proper management can easily obviate it, and, after all, the defect is not nearly so great as might at first sight be supposed; for in the four blades we have a total amount of reflecting surface very little short of the ordinary speculum of Bozeman or Sims. Moreover, in the small posterior coccygeal blade, which I have added for the purpose of keeping back the coccyx, as this otherwise interfered with the view, we gain still more of reflecting surface just at the part where the rays of light may be made available. As to the collapse of the vagina betweon the blades, I can only, in reply, oppose fact to imagination, for in practice the objection certainly does not exist.

In conclusion, I suppose that the drawings will explain themselves. Fig. 1 shows the three-bladed instrument closed. The two small side blades fall easily within the larger blade, making it very easy of introduction; while compression of the two handles together simultaneously expands the blades, as is shown in Fig. 2, thus separating the vaginal walls, and exposing them and the cervix uteri to view. Fig. 3 shows the four-, or perhaps I might rather call it the fivebladed instrument, closed for introduction; and no speculum can glide in more easily than it does. Fig. 4 represents the blades expanded, and the extent of surface thus exposed to view can be readily appreciated. The blades all open simultaneously by approximating the handles, as is shown in the drawing; they also collapse together for the purpose of withdrawal. In each instrument there is a small screw, by means of which the blades can be fixed at any point of expansion we may lesire, and the instrument will then maintain its position in the vagina without being held there, thus freeing both hands of the operator for any further proceeding which may be required.

I may add that the principle of the latter instrument is equally applicable to the rectum as to the vagina, and it appears to me to be as useful either for inspection or for operation. On this point, however, I have no experience, and must leave that for others to determine.

George-street, Hanover-square, May, 1870.

\section{ON THE HYDRATE OF CHLORAL.}

\section{By J. C. OGILVIE WILL, M.D.}

J. M-, suffering from severe facial neuralgia, brought on by exposure for six hours in an open boat after the sinking of the S.S. Gambia, applied for advice on the 28th of January. An eighth of a grain of morphia was injected subcutaneously at the site of the pain; immediate relief was experienced. He was also ordered to take a pill containing quinine, cannabis, and belladonna, one before an exacerbation was expected. The pain returned at the same hour as it had done for some days previous, when the hypodermic injection of morphia was again practised; after which he slept for a short time. The same treatment was employed during the four following days, when, as he was complaining much of want of rest, a draught containing twenty-five grains of hydrate of chloral was administered. In less than seven minutes be fell into a calm slumber, which lasted for eight hours; and in the morning expressed himself to be better in every way. The chloral was repeated each night till the patient was convalescent, with a like favourable result. I may add, that the inhalation of nitrite of amyl, which I have found useful in cases similar to this, was also tried, but produced only momentary relief.

In another most distressing case of neuralgia, where hypodermic injections of morphia and atropine, bromide of potassium in drachm doses, and opium in large quantities failed to induce sleep, a draught, containing a drachm of chloral, was ordered, half to be taken. This also failed; but, on the second half being given fifteen minutes after, five minutes later the patient was sound asleep, and did not awake for seven hours. On the following night a drachm was given; sleep followed immediately, but was not of so long duration as on the former occasion. For the ten following nights, two drachms were given; sleep invariably came on within five or six minutes, its duration varying from eight to twelve hours, and the patient awoke on every occasion without experiencing any of the unpleasant after-effects some have ascribed to this drug. On one occasion, on entering his room, I was much struck with the strong odour characteristic of chloral with which the air of the apartment was loaded. On examination, I found that it proceeded from his breath. This patient, so far as I can ascertain, is not in the habit of consuming much alcohol, and yet the dose required was much larger than I have found necessary in some cases of nervous excitement following fits of drinking. This is contrary to the experience of some, who state that the dose of chloral should be in proportion to the amount of alcohol the patient is in the habit of imbibing.

In several cases of bronchitis where insomnia, from the severity of the cough, had been a constant and most distressing symptom, chloral, in quantities varying from thirty grains to a drachm, has proved invaluable; the patients sleeping for seven or eight hours, and in the morning having only an indistinct remembrance of having coughed during the night.

In whooping-cough chloral has not proved a very efficient weapon in $\mathrm{my}$ hands; but in some other diseases of infancy, as in some varieties of convulsions, more especially those arising from irritability during teething, in small doses (four grains for a child eight months old) it has had excellent effects.

My appreciation of chloral, from a pretty large experience of it, is, that when a hypnotic is indicated, we possess in it an efficient and safe one-more certain than bromide of potassium, and without the unpleasant after-effects of opium and its preparations.

Aberdeen, March 19th, 1870.

\section{ON A NEW ARTERY FORCEPS, BY C. S. JEAFFRESON, EsQ.}

THE subject of arresting arterial bæmorrhage has given rise to some of the most animated and interesting discussions in the history of modern surgery; and so exhaustive have been the inquiries upon the subject that, in a pathological point of view, one can look for but little in the future. Not so in the mechanical, from which much may yet be expected.

'The instrument which $\mathrm{I}$ have devised and described below is meant to supersede the ligature, torsion, or acupressure, though it is readily applicable to the two former methods of arresting hæmorrhage, and, indeed, has advantages over the ordinary forceps employed for carrying them out. The principle of the new method is to draw the bleeding artery within a small metallic ring (ustually lead). This is forcibly compressed, and the artery then liberated, hæmorrhage being effectually controlled by the compressed and flattened ring. With a little practice, the instrument can be used with the greatest ease and facility, one hand alone being required.

The only pathological point involved is the question of the toleration of the tissues to these minute metallic bodies. Hitherto, in the few cases which I have tried, they have been found to produce no irritating or deleterious effects; the wound heals over them, and they either corrode and disappear or become encysted. This will, I believe, almost invariably occur where they are placed upon arteries situated 
deeply in the tissues, as femorals, popliteals, tibials; and for arteries of smaller size it is seldom that anything but torsion is necessary. Should the instrument be required for the application of an ordinary ligature, it will be found to draw it from its sheath in a manner which much facilitates its application, and the forceps secure it so firmly that it can never slip from the grasp. Should the operator wish to apply torsion, the handle of the instrument, with the forceps, can be rupidly rotated, and at the end of the torsion the forcible application of the clamp tends to close the vessel more firmly and securely. Again, in certain situations, where it is found impossible, or at least extremely difficult, to apply a ligature, this instrument will be found invaluable, as in operations upon the neck of the uterus or the back of the throat.

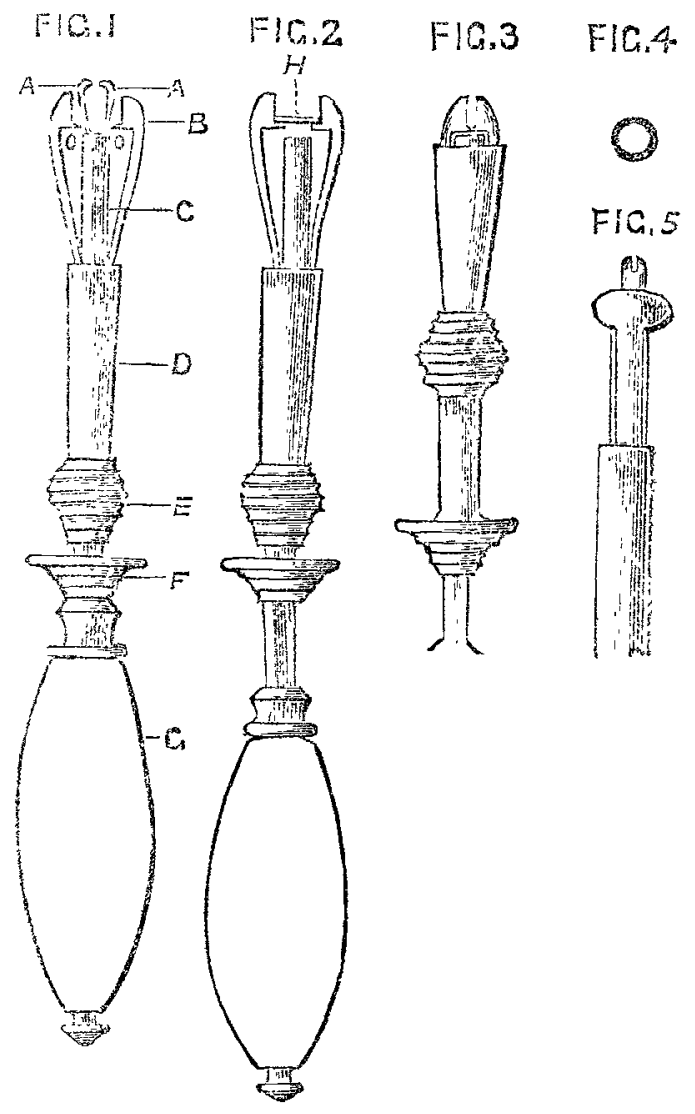

The "artery clamp forceps", which is here represented on a reduced scale, consists of two canulæ, Fig. 1 (c and $D$ ); a pair of forceps (A A), and the clamp $B$, with its fellow of the opposite side. When it is required to put the instrument into operation, a small leaden ring (Fig. 4) is passed over the ends of the forceps, and made to rest upon the ledges ( $O$ ) of the clamps. This is best seen in Fig. 2 (). The instrument is now ready for use. The artery being brought within grasp of the forceps, $F$ is pushed upwards; this causes the handle a to descend, and, being connected with the forceps, it draws them within the canula $\mathrm{c}$, carrying with them the artery, the end of which is thus drawn within the circumference of the leaden ring. This is best understood by referring to Fig. 2, where the instrument is represented with the forceps drawn into the canula. The next movement consists of clamping the leaden ring. The handle $\mathrm{E}$ of the canula $\mathrm{D}$ is now pushed upwards; it causes the clamps to approach each other gradually, and thus flatten the ring. This is shown in Fig. 3 , where the instrument is represented with the clamps closed. The operation is now complete: the canula $\mathrm{D}$ is again brought down, liberating the clamps; the handle of is pushed up, causing the forceps to protrude and liberate the artery, which is found securely fastened by the compressed ring.

The instrument is admirably manufactured by Messrs. Weiss and Sons, of the Strand, London.

Newcastle-on-Tyne, April, 1870.

AN outbreak of small-pox is reported from Kingstonon-Thames. The district medical officers have reported 18 cases, and 8 cases appear to have occurred in the workhouse.

\section{A a dithror}

OF THE PRACTICE OF

\section{MEDICINE AND SURGERY IN THE}

HOSPITALS OF LONDON.

Nulla autem est alia pro certo noscendi via, nisi quamplurimas et morborum et dissectionam historias, tum aliorum, tum proprias collectas habere, et inter se comparare.-MIorgagni De Sed. et Caus. MTorb., lib. iv. Proœmium.

\section{KING'S COLLEGE HOSPITAL.}

(Ophthalmic Department.)

ABSCESS OF THE FRONTAL SINUS; OPERATION; CURE.

(Under the care of Mr. Somuberg Wells.)

THe following is an example of very successful treatment of a troublesome and disfiguring affection :-

R. S-, aged forty, a baker, perceived, about twelve years ago, that the right upper eyelid was swollen, and hung down over the eye. This swelling disappeared spontaneously in the course of a week, but recurred about every two years; and six months ago he noticed that, besides the tumefaction of the lid, there was a small swelling at the inner angle of the upper lid close to the root of the nose. As this gradually increased in size, he applied for advice at King's College Hospital on the 4th June, 1869. He then presented the following appearance:-The right eye protrudes considerably, and is displaced so much downwards and outwards that the upper edge of the cornea is below the level of the left lower lid. (See Fig. 1.) The movements of the eyeball are greatly curtailed, both upwards and inwards.

FIG. 1.

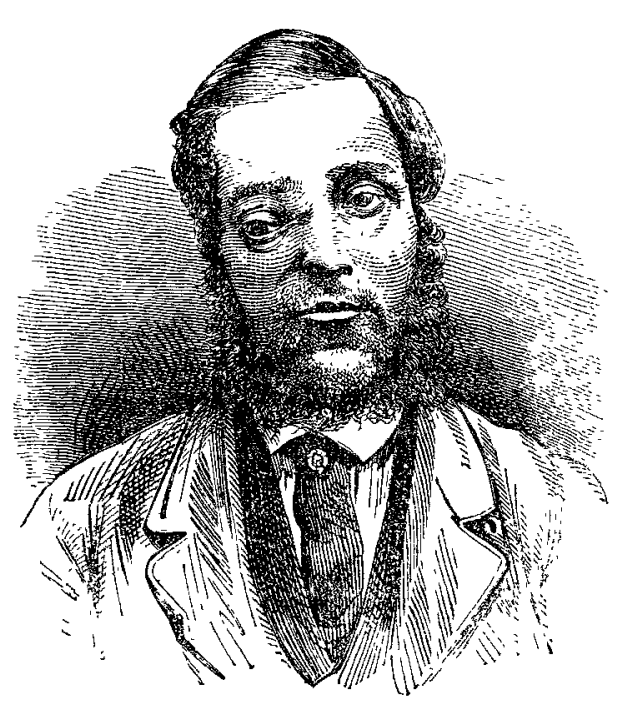

The upper lid is red, and considerably swollen; and at its inner angle is noticed an oval, tolerably defined tumour, about the size of a large hazel-nut, which extends up to the eyebrow. But the nasal prominence on this side is only very slightly enlarged. The outline of the upper and lower margin of the orbit can be easily traced with the finger, and is found to be sharply defined, and not at all swollen, or concealed by any tumour. The oval swelling, though firm and tense, is elastic, yields a distinct sense of fluctuation, and is slightly tender to the touch; the patient also experiences some dull pain, extending from the inner corner of the eye outwards over the orbit. The eye is somewhat injected, and becomes irritable and watery on exposure to cold winds or bright light. The sight and visual field, however, are good, and the fundus oculi is quite normal; and the exophthalmos, and consequent stretching of the optic nerve, have not produced any hyperæmia or odema of the retina or optic nerve.

Mr. Wells considered that the case was in all probability 